\title{
Author response to "lack of benefit from low dose computed tomography in screening for lung cancer"
}

\author{
Kai-Lin Huang ${ }^{1,2}$, Shih-Yuan Wang ${ }^{1}$, Wan-Chen Lu', Ya-Hui Chang ${ }^{1}$, Jian Su ${ }^{3,4^{*}+}$ and Yen-Ta Lu $u^{3,4^{*+}}$
}

\begin{abstract}
We explain to Dr. Benjamin (corresponding author) about why low-dose computed tomography reduce lung cancer mortality without significantly reducing all-cause mortality. We also conduct an up-to-date meta-analysis to evaluate low-dose computed tomography clinical effectiveness compared with usual care of lung cancer screening.
\end{abstract}

Keywords: Low-dose computed tomography, LDCT, Lung cancer screening, Mortality, Meta-analysis

\section{Author response}

Dr. Benjamin points out that the inconsistencies between lung cancer mortality and all-cause mortality in our article [1] [low-dose computed tomography (LDCT) reduced lung cancer mortality (rate ratio (RR) $0.83,95 \%$ confidence interval (CI) $0.76-0.90, \mathrm{I}^{2}=1 \%$ ) but had no effect on all-cause mortality (RR 0.95 , 95\% CI $0.90-$ 1.00)]. We agree and acknowledge in our abstracts. The data shows that all-cause mortality is moving in the same direction as lung cancer mortality (favor LDCT), even if statistical significance cannot be demonstrated. We also agree that mortality benefits of screening trial require cautious scrutiny. The accuracy of lung cancer mortality depends on identifying the cause of death accurately which may be subject to bias. Therefore, allcause mortality should be reported and considered together with lung cancer mortality [2].

Three trials recently update their extended follow-up data [National Lung Screening Trial (NLST) [3], Nederlands-Leuvens Longkanker Screenings Onderzoek

This reply refers to the comment available at https://doi.org/10.1186/s12890020-01252-1.

*Correspondence: jiansu@mmh.org.tw; ytlhl@mmh.org.tw

† Jian Su and Yen-Ta Lu contributed equally to this work.

${ }^{3}$ Department of Chest Medicine, MacKay Memorial Hospital, No. 92, Sec. 2, Zhongshan N. Rd, Taipei City 10449, Taiwan

Full list of author information is available at the end of the article
Study (NELSON) [4] and German Lung Cancer Screening Intervention Trial (LUSI) [5]]. We have re-analyzed the data by using the latest mortality rate (shown in Fig. 1). The lung cancer mortality rate ratio is $0.86(95 \%$ CI $\left.0.79-0.93, \mathrm{I}^{2}=0 \%\right)$. For all-cause mortality, rate ratio is 0.98 (95\%CI $0.95-1.01)$. We also conduct sensitivity analyses to test the robustness of the results. The leaveone-out analysis is performed by omitting one study in turn. Even when we exclude NLST trial (which Dr. Benjamin think it might have potential methodological flaws), results are still robust. The outcome is consistent with our previous analysis. As suggested by Prasad et al. [6] and Dr. Benjamin, limited evidence shows that chest radiography (CXR) may increase death from lung cancer, in which some deaths are attributed to detected cancer incorrectly. Thus, no screening (usual care) would be a more appropriate comparator. In the subgroup from our analyses indicate that, compare with no screening (usual care), LDCT screening still has effect in reduction lung cancer mortality (RR 0.83, 95\% CI 0.71-0.91).

There are several possible explanations why LDCT reduce lung cancer mortality without significantly reducing all-cause mortality. To begin with, some of the inconsistencies observed may be due to chance, in particular when lung cancer mortality is proportionally low. Pooling of the available data in a meta-analysis may 
A

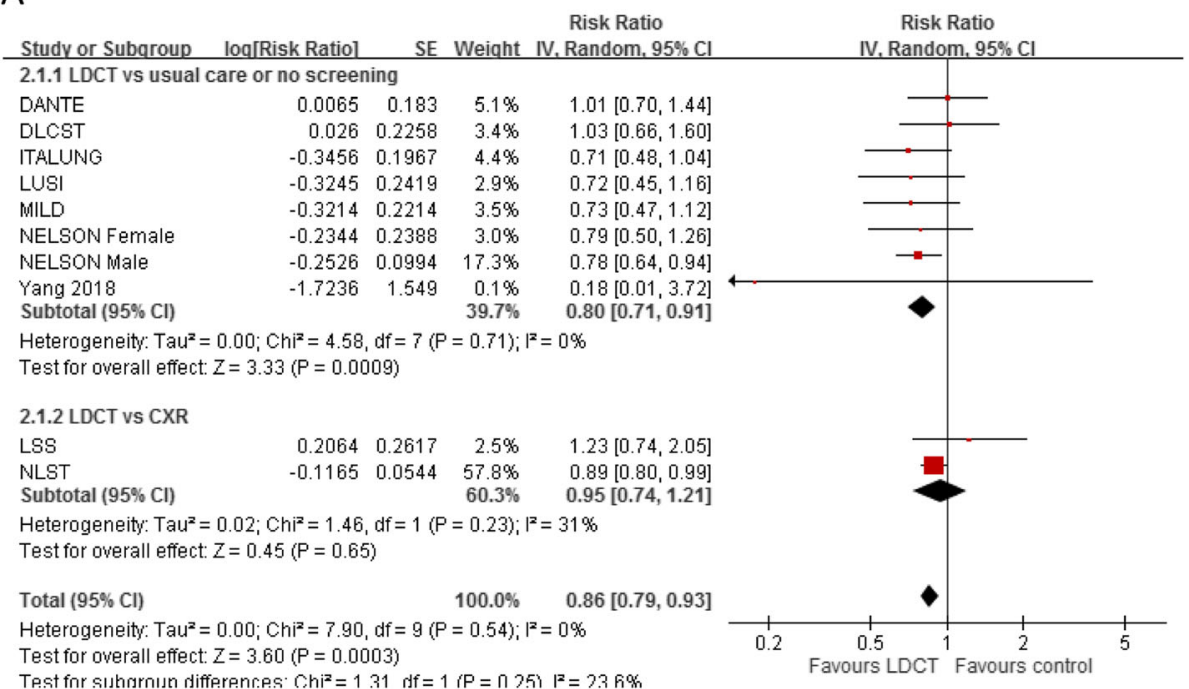

B

\begin{tabular}{|c|c|c|c|c|c|c|c|c|}
\hline Study or Subqroup & log[Risk Ratio] & SE & Weight & $\begin{array}{c}\text { Risk Ratio } \\
\text { IV, Random, } 95 \% \mathrm{Cl}\end{array}$ & & $\begin{array}{r}\text { Risk Ra } \\
\text { IV, Random. }\end{array}$ & $\begin{array}{l}\text { Ratio } \\
\mathrm{n}, 95 \% \mathrm{Cl}\end{array}$ & \\
\hline DANTE & -0.0412 & 0.098 & $2.5 \%$ & $0.96[0.79,1.16]$ & & & & \\
\hline DLCST & 0.0122 & 0.1059 & $2.1 \%$ & $1.01[0.82,1.25]$ & & & & \\
\hline ITALUNG & -0.174 & 0.1038 & $2.2 \%$ & $0.84[0.69,1.03]$ & & & & \\
\hline LSS & 0.1797 & 0.1209 & $1.6 \%$ & $1.20[0.94,1.52]$ & & & & \\
\hline LUSI & -0.0164 & 0.1115 & $1.9 \%$ & $0.98[0.79,1.22]$ & & & & \\
\hline MILD & -0.0648 & 0.1254 & $1.5 \%$ & $0.94[0.73,1.20]$ & & & & \\
\hline NELSON Male & 0.01 & 0.0476 & $10.4 \%$ & $1.01[0.92,1.11]$ & & & & \\
\hline NLST & -0.021 & 0.0174 & $77.8 \%$ & $0.98[0.95,1.01]$ & & & & \\
\hline Total $(95 \% \mathrm{Cl})$ & & & $100.0 \%$ & $0.98[0.95,1.01]$ & & & & \\
\hline \multicolumn{5}{|c|}{$\begin{array}{l}\text { Heterogeneity: } \operatorname{Tau}^{2}=0.00 ; \mathrm{Chi}^{2}=5.59, \mathrm{df}=7(P=0.59) ; \mathrm{I}^{2}=0 \% \\
\text { Test for overall effect: } Z=1.19(\mathrm{P}=0.23)\end{array}$} & 0.7 & $\begin{array}{l}0.85 \\
\text { ours LDCT }\end{array}$ & $\begin{array}{r}1.2 \\
\text { Favours co }\end{array}$ & 1.5 \\
\hline
\end{tabular}

Fig. 1 Forest plots of comparisons between low-dose computed tomography (LDCT) versus no screening or chest radiology (CXR) for (a) lung cancer mortality (b) all-cause mortality using update data

solve the problem. Then, if the percentage of cancer deaths among all deaths is low, there isn't much risk to reduce. Even for a useful cancer screening procedures, the effect would be small in absolute terms (in the case of NELSON, a $24 \%$ decrease in the relative risk of dying of lung cancer in men translated to an approximately $0.75 \%$ reduction in lung cancer mortality (from $3.18 \%$ in the control group to $2.43 \%$ in the LDCT group) after 10 years of follow-up) [4]. Thus, reduction in lung cancer mortality with LDCT screening is too low to considerably affect all-cause mortality. Furthermore, studies may not be sufficiently powered to detect a possible favorable difference in all-cause mortality. According to Heijnsdijk et al. [7], a significant reduction in all-cause mortality could be expected between 11 and 13 years of follow-up for a sample size of minimal 40,000 high risk participants in each arm. Studies included in our meta-analysis have sample sizes far below 80,000 and some of trials less than 11 years of follow up. One cannot expect statistically significant declines in all-cause mortality. Finally, subsequent deaths from cancers develop after the screening window and other causes of death appear [3]. It will lead to a trend towards a reduced difference between two groups and diminishing levels of significance. It would be unrealistic to expect a single intervention designed to contribute to reduced mortality from one cause to reduce mortality from all causes. After all, the primary aim of cancer screening is to prevent premature death from one or several related causes.

However, harms of future invasive procedures for diagnosis purpose, overdiagnosis and overtreatment cannot be fully accounted by using lung cancer mortality as outcome. All-cause mortality reductions may be offset by harms due to the LDCT screening. Although LDCT shows an increase in detection of early stage cancers, overdiagnosis and false positive test results may increase as well. These results in unnecessary diagnostic procedures and lead to unnecessary treatment. When the possible benefits and harms of each option affect patients differently, shared decision making is 
recommended. Besides, targeting high risk population and image analysis methods refinement may further improve the efficiency of LDCT screening.

Since lung cancer is the leading cause of cancerrelated death among men and women, if it is found at an earlier stage, it is more likely to be successfully treated. Prevention (e.g. smoking cessation) is likely to have far greater impact on lung cancer mortality than is screening. Nonetheless, LDCT screening has the potential to significantly reduce the burden of lung cancer. From a public health perspective, $14 \%$ reduction in lung cancer mortality and $2 \%$ reduction in all-cause mortality (even though the effect is not statistically significant) may be relevant. More studies are warranted to optimize risk-stratified recruitment strategies and radiologic criteria.

\section{Abbreviations}

LDCT: Low-dose computed tomography; RR: Rate ratio; Cl: Confidence interval; NLST: National Lung Screening Trial; NELSON: Nederlands-Leuvens Longkanker Screenings Onderzoek Study; LUSI: German Lung Cancer Screening Intervention Trial; CXR: Chest radiography

\section{Acknowledgements}

Not applicable.

\section{Authors' contributions}

Study conception or design: KLH, SYW, WCL, YHC, JS and YTL. Data acquisition: KLH, SYW, WCL and YHC. Data analysis or interpretation: KLH and SYW. Manuscript drafting: KLH and SYW. Critical manuscript revision: KLH, SYW, WCL, YHC, JS and YTL. Final manuscript approval: KLH, SYW, WCL, YHC, JS and YTL.

\section{Funding}

This research received no specific grant from any funding agency in the public, commercial or not-for-profit sectors.

\section{Availability of data and materials}

All data generated or analyzed during this study are included in this published article.

\section{Ethics approval and consent to participate}

Not applicable.

\section{Consent for publication}

Not applicable.

\section{Competing interests}

The authors declare that they have no competing interests.

\section{Author details}

${ }^{1}$ Department of Pharmacy, MacKay Memorial Hospital, No. 92, Sec. 2 , Zhongshan N. Rd, Taipei City 10449, Taiwan. ${ }^{2}$ Mackay Junior College of Medicine, Nursing, and Management, No.92, Shengjing Road, Beitou District, Taipei 11272, Taiwan. ${ }^{3}$ Department of Chest Medicine, MacKay Memorial Hospital, No. 92, Sec. 2, Zhongshan N. Rd, Taipei City 10449, Taiwan. ${ }^{4}$ Department of Medicine, Mackay Medical College, No.46, Sec. 3, Zhongzheng Rd., Sanzhi Dist, New Taipei City 252, Taiwan.

Received: 26 May 2020 Accepted: 27 July 2020

Published online: 26 August 2020

\section{References}

1. Huang K-L, Wang S-Y, Lu W-C, Chang Y-H, Su J, Lu Y-T. Effects of low-dose computed tomography on lung cancer screening: a systematic review, meta-analysis, and trial sequential analysis. BMC Pulm Med. 2019;19(1):126.
2. Black WC, Haggstrom DA, Gilbert Welch H. All-cause mortality in randomized trials of Cancer screening. J Natl Cancer Inst. 2002;94(3):167-73.

3. Aberle DR, Black WC, Chiles C, Church TR, Gareen IF, Gierada DS, Mahon I, Miller EA, Pinsky PF, Sicks JD. Lung cancer incidence and mortality with extended follow-up in the national lung screening trial. J Thorac Oncol. 2019;14(10):1732-42

4. de Koning HJ, van der Aalst CM, de Jong PA, Scholten ET, Nackaerts K, Heuvelmans MA, Lammers JJ, Weenink C, Yousaf-Khan U, Horeweg N, et al. Reduced lung-cancer mortality with volume $\mathrm{CT}$ screening in a randomized trial. N Engl J Med. 2020;382(6):503-13.

5. Becker N, Motsch E, Trotter A, Heussel CP, Dienemann H, Schnabel PA, Kauczor HU, Maldonado SG, Miller AB, Kaaks R, et al. Lung cancer mortality reduction by LDCT screening-results from the randomized German LUSI trial. Int J Cancer. 2020;146(6):1503-13.

6. Prasad V, Lenzer J, Newman DH. Why cancer screening has never been shown to "save lives"--and what we can do about it. BMJ. 2016;352:h6080.

7. Heijnsdijk EAM, Csanádi M, Gini A, Ten Haaf K, Bendes R, Anttila A, Senore C, de Koning HJ. All-cause mortality versus cancer-specific mortality as outcome in cancer screening trials: a review and modeling study. Cancer Med. 2019;8(13):6127-38

\section{Publisher's Note}

Springer Nature remains neutral with regard to jurisdictional claims in published maps and institutional affiliations.

\section{Ready to submit your research? Choose BMC and benefit from:}

- fast, convenient online submission

- thorough peer review by experienced researchers in your field

- rapid publication on acceptance

- support for research data, including large and complex data types

- gold Open Access which fosters wider collaboration and increased citations

- maximum visibility for your research: over $100 \mathrm{M}$ website views per year

At BMC, research is always in progress.

Learn more biomedcentral.com/submissions 